\title{
The Use of Subtitled Films with a Frame Reduction Plate in Foreign Language Teaching
}

\author{
by Hart Wegner and R. Kent Look
}

The father of film, D. W. Griffith, predicted in The Editor in 1915, that in less than ten years the time would come when "the children in public schools will be taught practically everything by moving pictures." The prophecy was somewhat hasty, but by now film is used to teach almost any subject including foreign languages.

The use of film in departments teaching any of the foreign languages is certainly not new, but greater emphasis seems to have been placed on its utilization in the last 15 years. In the past, primarily three kinds of films were used in the foreign language classroom:

\section{The Pedagogic Film.}

Specific problem areas of instruction (pronunciation and grammar problems, etc.) are either illustrated in a straight instructional manner with closeups of the screen-instructor's mouth or else dramatized in sketches and scenes, often lightly humorous. Both approaches are intended to present speakers to the student who pronounce clearly, who slow down their pace of speaking, and who never have even a faint trace of an accent, so much so that the screen language bears hardly any resemblance to the language spoken in its natural environment. The natural linkage of words is destroyed, thereby facilitating the formation of a sort of accent in the language learner.

In dealing with students who are relatively sophisticated when it comes to visual material and techniques of filmmaking, most of the educational film products of this type do not promise to hold the attention of the class, and material selected for foreign language instruction should aim to be technically superior to these products produced in an amateur fashion and leavened with sophomoric humor. The aim of the instructor should be to provide visual and aural instruction which at least attempts to reach the technical level of accomplishment of a television commercial. The low production budget of most such pedagogic films is readily evident and they prove to be unappealing to a generation of students who, during their formative years, were exposed to daily doses of film and television.' 


\section{The Culture and Industry Short.}

Films in this category, produced as a mild form of cultural propaganda, are almost always supplied free of charge by consulates and embassies. Their value in teaching a foreign language is limited, and they are usually destined for the culture and civilization courses. ${ }^{2}$

\section{Illustrated Literature.}

For many years feature length films were projected in the foreign language classroom only as filmed literary masterpieces. Such films were frequently shown after the novel or drama had been read in class. Rarely did the cinematic values matter to the instructor who selected the film, as long as the Comedie Francaise was featured or the Burgtheater performed Schiller.

The marked reluctance of many language instructors to use feature films which are not filmed literature seems surprising, because the benefits for the language learners are many. Films like Renoir's La Regle du Jeu and La Grande Illusion not only offer French dialog to the class, but are cinematic masterpieces, conceived from a strong sense of literature and culture in its noblest sense, and they create and recreate France in the XXth century in a way no culture and civilization textbook can hope to do.

Major obstacles in the path of more widespread film use are the lack of knowledge about film, its history, and its technical language among instructors who would like to use film as a creative tool in the teaching of a second language. A lack of readily available funds for film rental is another hurdle which needs to be overcome. More problematic is the prejudice and even hostility of the print-oriented towards film as a legitimate form of literature. Originating from the conventions of the Victorian novel, film form and language developed very pointedly as literature, and the narrative techniques of the cinema are literary. ${ }^{3}$ The legitimacy of film as literature does not have to be proven again and again and film does not become acceptable literature merely by copying literary masterpieces.

In all fairness, it should be added that prejudice towards the use of film in teaching foreign languages does not stem solely from the "Gutenberg" quarters of language and literature departments. For years the purists among film instructors have felt that film, being an autonomous art form, should not be used in an ancillary fashion to teach anything. This argument is reminiscent of the observation in the introduction to The Picture of Dorian Gray: "All art is quite useless." Strangely enough D. W. Griffith, to whose films and cinematic innovations world film is obligated, felt no compulsion to limit the practical application of film and he envisioned a limitless didactic potential in the future of film. These obstacles to the use of film in teaching languages can be eliminated 
in time through a spirit of experimentation, the dissemination of film information especially aimed at the needs of foreign language instructors, the publication of reliable textbooks using film as a basis, and a helping hand by those who already use film creatively.

To the three categories of film utilization in the language departments a fourth one should be added:

\section{The Foreign Language Feature Film.}

The teaching of language is the field within our disciplines where the reasons for the use of feature films for instructional purposes are most persuasive: A. The primary production and marketing thrust of a theatrical release film is obviously directed at the native audience (although in many film producing countries, especially with smaller local markets, export considerations are vital concerns) and these films reflect the rulture, history, ideological concerns, and, above all, they mirror the people whose language is the concern of our instruction; $B$. The language spoken in the film is directed at a native audience, without concessions to the learner, recreating the conditions a student will encounter when travelling and conversing with natives; C. These films do not reveal a didactic purpose, which almost always is a positive point in a classroom situation; D. Detailed work with a carefully chosen film may become one of the major projects of a term. The continuous involvement of instructor and students in the film project helps to build and maintain motivation and enthusiasm, still the greatest of necessities in the teaching and learning of a foreign language; E. Feature films have a multiple use potential. The film and its script can be combined to become the basic material for in-class use. The soundtrack can be divided into individual assignment segments in the language laboratory. Students can study individual roles in the film and read from the script following along with the silenced film and taped versions can be checked against the screen originals; 4 F. Having a film on campus for an extended period of time means it can also be projected in literature, civilization and culture courses, depending upon the selection of the film.

The problems faced by an instructor who wishes 10 use film in the classroom are manifold and unfortunately they often tend to discourage the novice. A particularly time-consuming and annoying problem is the lack of readily available foreign language films without subtitles.

To be sure, foreign films in their original form (without dubbing or subtitling) can be obtained in the United States. In some instances embassies provide feature films, usually free of charge. Since only a limited number of prints are circulated (occasionally one single print has to suffice for all schools, colleges, and organizations in the U.S.) it becomes increasingly difficult 10 receive assurance of a playdate, unless one orders 
nine months or a year ahead of time. Even then the arrival of the film for the playdate is not guaranteed and the film has to be returned immediately after one showing. Turning to commercial distributors of foreign language films such as the Columbia Cinematheque, Contemporary/McGraw Hill, Janus Films, or Macmillan Audio Brandon, we find that reliability, print quality, and reasonable scheduling can be listed on the plus side as compared to the non-commercial sources. Unfortunately, however, prints are almost always subtitled and thus unacceptable for foreign language instruction, because the subtitles provide the learner with an instant "interlinear" translation.

A number of attempts to solve the problem of the ubiquitous subtitles were made in the Language Laboratory at the University of California, Berkeley. Different means of obliterating them were tried and abandoned The lower portion of the screen was masked in black, but the print 0 the subtitles changes from black to white depending on the most prom inent background of the scene. The lower portion of the projector's len:; was taped, but the diffusion of the light makes this useless, just as the attempt to tape the pressure plate within the projector failed because the heat destroys the tape.

Precedent exists for cropping a projected image, although generally only changes to the removable aperture plate in $35 \mathrm{~mm}$ and $70 \mathrm{~mm}$ projectors are discussed. Professional projection facilities would normally have a set of custom-filed aperature plates to correct keystoning (related to projection vs. screen placement) or other projection difficulties related to curved screens.5 Unfortunately, the aperture plate of most $16 \mathrm{~mm}$ projectors is not readily removable for alteration or easy interchange though the pressure plate or "shoe" is easy to remove and exchange. Two screws or retaining rings are normally all that is involved. Modification of this part of a $16 \mathrm{~mm}$ projector has proved to be a totally acceptable solution for the subtitle problem.

The modification is quick, simple, and has been completed on both Bell and Howell and Singer-Graflex projectors to date. It requires approximately one half hour of time separated into two working sessions with an interval of $\mathbf{2 4}$ hours as a drying period between the sessions. Equipment needs are one small file no wider than $3 / 8$ inch (smaller files seem easier to use and even an emery board will suffice if need be), a tube of plastic metal (aluminum and steel have proven satisfactory, steel being somewhat more durable for repeated handling), a piece of tape approximately $1 / 2$ inch by 1 inch, a medium small screwdriver, and a permanent black felt marking pen.

The pressure plate already mounted in the projector can be modified and, when necessary, the modification can be removed. Unsubtitled films can be shown with the modified plate in place with generally acceptable image loss. A more practical solution would be to purchase a second pressure plate (cost: $\$ 10$ to $\$ 15$ ) that can be made into a frame 
reduction plate and used interchangeable with the regular plate when needed. Changing a pressure plate normally takes less than ten minutes.

To accomplish the modification, locate and remove the pressure plaie from the projector, having noted and marked the top with the felt tip. Carefully clean away the blacking on the inside of the hole. Plate the piece of tape over the projection hole, on the side of the plate not facing the film. Express about $1 / 2$ teaspoon of the plastic metal onto a disposable non-absorbent surface. Quickly mix it lightly to eliminate any air bubbles and fill in completed $1 / 3$ to $1 / 2$ of the top of the opening. There is no need to apply the plastic any thicker than the thickest part of the pressure plate. Allow the plastic metal to dry for twenty-four hours. Remc.ve the tape and then, using the fine file, restore the original contours of both sides of the plate, being careful not to damage the edge ridges which press against the film. Carefully and slowly work the exposed edge so that it becomes flat and parallel to the unaltered bottom edge. Clean and smooth the entire plate with fine steel wool. A t this point some trial and error work is in order. For the two Bell and Howell projectors modified at the University of California, Berkeley, we found that by enlarging the opening to a dimension of approximately $1 / 4$ inch (fifteen to sixteen sixty-fourths of an inch) allowed, with adjustment of the framer on the projector, cropping of two and three line subtitles.

After trying the modified plate in the projector with a subtitled film (using the framer you should be able to see just a very small portion of a three line subtitle with the framer in the extreme film lowered position) remove the plate from the projector and, if necessary eliminate more material. Repeat the testing process. Only very small increments of change are recommended at this point.

Once a satisfactory opening has been obtained, bevel the edge to about 30 degrees with the sharp edge facing the film, to preclude the effect of "fringing" at the bottom of the projected screen image. Clean the entire plate with fine steel wool giving special attention to the highly polished areas (runners) which contact the film. Blacken the entire inside of the opening with the felt tip to prevent reflections. Install the plate and check that it is properly seated.

The applied insert can be broken out with a little pressure either accidentally or, if you desire to return the plate to its original condition, by choice. When returning the plate to its original condition, be certain to remove all material and to blacken the inside edges of the hole.

The film purist may flinch at the mere mention of tampering with the usual aspect ratio of 1.33;1 but the basis esthetic damage has been done to the composition of the image when the subtitles were printed across the screen image in the first place. The frame reduction process actuallly removes from the lower portion of the image the visual clutter, which distracts and draws attention away from the composition of a shot. 
The frame reduction plate described above permits the use of the majority of subtitled films in foreign language classes. Furthermore, it enables the instructor to enjoy the greater reliability and improved print quality offered by commercial distributors and makes him independent of the consulates which might otherwise be the only source of untitled films

\section{NOTES}

'One of the most popular products among language-pedagogic films is the series Guten Tag!, produced by the Bayerischer Rundfunk with the Goethe-Institut on behalf of the Ministry of Foreign Affairs of the Federal Republic of Germany.

${ }^{2}$ The French film Library offers some shorts directed by feature filmmakers of note: Georges Franju, Robert Enrico, Agnes Varda, and Alain Resnais's documentary on the National Library in Paris Toute la Memoire du Monde.

3While shooting After Many Years Griffith was asked about his use of crosscutting: "How can you tell a story jumping about like that? The people won't know what it's about." "Well," said Mr. Griffith, "doesn't Dickens write that way?" "Yes, but that's Dickens; that's novel writing; that's different." "Oh, not so much, these are picture stories; not so different." Linda Arvidsen, When the Movies Were Young (New York: Dover Publications, 1969), p. 66.

${ }^{4} \mathrm{~A}$ detailed monograph on the multiple uses of feature films is in preparation for publication by the Educational Research Information Center (ERIC): Hart Wegner, Feature Films in Second Laguage Instruction.

sHoward M. Tremaine, Audio Cyclopedia. (New York: Howard W. Sams \& Co., Inc., 1969), pp. 1031-33. 

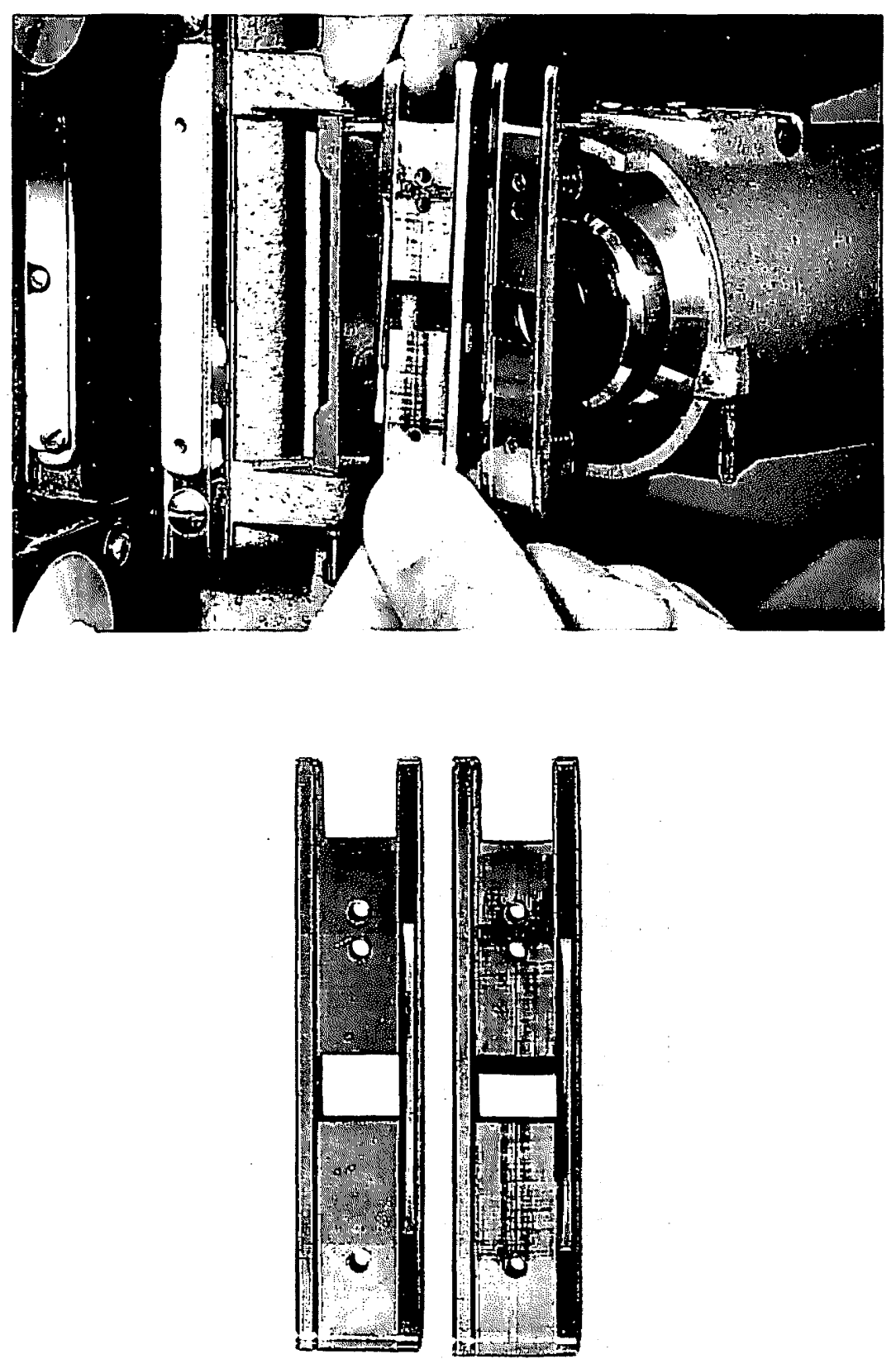